\title{
and cytokine expression and renal injury in cisplatin nephrotoxicity
}

\author{
Ganesan Ramesh ${ }^{1}$ and W. Brian Reeves ${ }^{1,2}$ \\ ${ }^{1}$ Division of Nephrology, Penn State College of Medicine, Milton S. Hershey Medical Center, Hershey, Pennsylvania, USA \\ ${ }^{2}$ Lebanon Veterans Administration Medical Center, Lebanon, Pennsylvania, USA
}

\begin{abstract}
The purpose of these studies was to examine the role of cytokines in the pathogenesis of cisplatin nephrotoxicity. Injection of mice with cisplatin $(20 \mathrm{mg} / \mathrm{kg})$ led to severe renal failure. The expression of cytokines, chemokines, and ICAM- 1 in kidney was measured by ribonuclease protection assays and RT-PCR. We found significant upregulation of TNF- $\alpha$, TGF- $\beta$, RANTES, MIP-2, MCP- 1 , TCA3, IL-1 $\beta$, and ICAM-1 in kidneys from cisplatin-treated animals. In addition, serum, kidney, and urine levels of TNF- $\alpha$ measured by ELISA were increased by cisplatin. Inhibitors of TNF- $\alpha$ production (GM6001, pentoxifylline) and TNF- $\alpha$ Ab's reduced serum and kidney TNF- $\alpha$ protein levels and also blunted the cisplatin-induced increases in TNF- $\alpha$, TGF- $\beta$, RANTES, MIP-2, MCP-1, and IL- $1 \beta$, but not ICAM-1, mRNA. In addition, the TNF- $\alpha$ inhibitors also ameliorated cisplatin-induced renal dysfunction and reduced cisplatin-induced structural damage. Likewise, TNF- $\alpha$-deficient mice were resistant to cisplatin nephrotoxicity. These results indicate cisplatin nephrotoxicity is characterized by activation of proinflammatory cytokines and chemokines. TNF- $\alpha$ appears to play a central role in the activation of this cytokine response and also in the pathogenesis of cisplatin renal injury.
\end{abstract}

J. Clin. Invest. 110:835-842 (2002). doi:10.1172/JCI200215606.

\section{Introduction}

Cisplatin is an effective chemotherapeutic agent used in the treatment of a wide variety of both pediatric and adult malignancies (1). Dose-dependent and cumulative nephrotoxicity is the major toxicity of this compound, sometimes requiring a reduction in dose or discontinuation of treatment. Approximately $25-35 \%$ of patients develop evidence of nephrotoxicity following a single dose of cisplatin (2).

Much attention has been focused on the direct toxic effects of cisplatin in renal tubular cells in vitro (2). In this setting, cisplatin induces DNA damage $(2,3)$, mitochondrial dysfunction (4), formation of reactive oxygen species (5), caspase activation (6), and either necrotic or apoptotic cell death, depending on the concentration of cisplatin $(7,8)$. In ischemic acute renal injury, inflammatory mechanisms appear to play an important role in the pathogenesis $(9,10)$. However, there is little information available regarding the role of inflammatory cells and cytokines in toxic nephropathy $(11,12)$.

The molecular mechanisms and mediators responsible for inflammatory injury in either ischemic or toxic acute renal failure remain undefined. Oxidant stress,

Received for publication April 3, 2002, and accepted in revised form July 9, 2002.

Address correspondence to: W. Brian Reeves, Division of Nephrology, H040, Penn State College of Medicine, 500 University Drive, Hershey, Pennsylvania 17033, USA. Phone: (717) 531-8156; Fax: (717) 531-6776; E-mail: Wreeves@psu.edu.

Conflict of interest: No conflict of interest has been declared.

Nonstandard abbreviations used: body weight (BW); multiprobe ribonuclease protection assay (RPA). present in both ischemic and cisplatin-induced injury (13-15), is an activator of the NFKB transcription factor, which, in turn, promotes the production of proinflammatory cytokines, including TNF- $\alpha$ (16). TNF- $\alpha$ mRNA is increased in both ischemic and cisplatin renal injury (12). However, a systematic examination of cytokine expression in cisplatin nephrotoxicity has not been reported. Likewise, the role of specific cytokines and chemokines in the pathogenesis of cisplatin nephrotoxicity has not been examined.

The purpose of the present study was to determine the profile of kidney cytokine gene expression in cisplatin nephrotoxicity and to examine the role of TNF- $\alpha$ in the pathogenesis of cisplatin-induced acute renal failure. We used ribonuclease protection assays and quantitative RT-PCR to measure the levels of mRNA for 30 chemokines and cytokines in kidneys from mice treated with nephrotoxic doses of cisplatin. Additional studies employed inhibitors of TNF- $\alpha$ release or activity and mice lacking a functional TNF- $\alpha$ gene to assess the role of TNF- $\alpha$ in the transcriptional, functional, and histologic sequelae of cisplatin administration. The results indicate that TNF- $\alpha$ is a key element in a network of proinflammatory chemokines and cytokines activated in the kidney by cisplatin. Blockade of TNF- $\alpha$ action prevents the activation of this cytokine network and provides protection against cisplatin nephrotoxicity.

\section{Methods}

Animals and drug administration. Except when indicated experiments were performed on 8- to 9-week-old male Swiss-Webster or TNF- $\alpha$ knockout mice weighing 


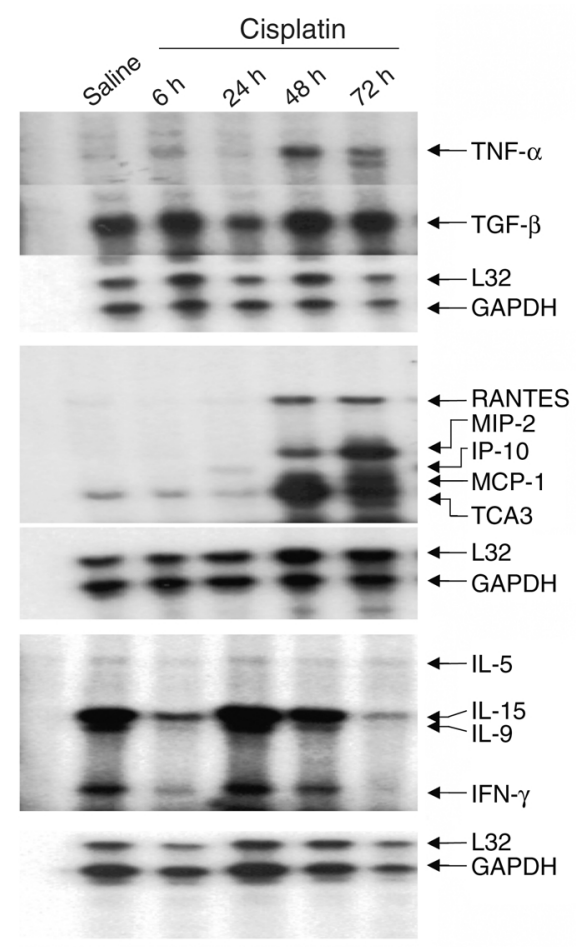

\section{Figure 1}

Time course of gene expression in cisplatin nephrotoxicity. Mice were injected with either saline (first lane) or $20 \mathrm{mg} / \mathrm{kg}$ cisplatin, sacrificed at the indicated times, and total RNA was isolated from the kidney. Levels of cytokine transcripts were measured by RPA as described in Methods.

$20-25$ g. The TNF- $\alpha$ knockout mice (strain B6,129Tnf ${ }^{\mathrm{tm} 1 \mathrm{Gkl}}$ ) and the control mice (B6129SF2/J) were obtained from The Jackson Laboratories (Bar Harbor, Maine, USA.) (17). Mice were maintained on a standard diet, and water was freely available. Cisplatin (Sigma-Aldrich, St. Louis, Missouri, USA) was dissolved in saline at a concentration of $1 \mathrm{mg} / \mathrm{ml}$. Mice were given a single intraperitoneal injection of either vehicle (saline) or cisplatin $(20 \mathrm{mg} / \mathrm{kg}$ body weight [BW] ). This dose of cisplatin produces severe renal failure in mice (18). Some groups also received TNF- $\alpha$ antagonists such as GM6001 or its inactive analogue GM6001(-) (10 mg/kg BW every 24 hours), neutralizing $\mathrm{Ab}(800 \mu \mathrm{g} / \mathrm{kg} \mathrm{BW}$ as a single dose $)$, or pentoxifylline ( $150 \mathrm{mg} / \mathrm{kg} \mathrm{BW}$ every 12 hours). Blood was collected every 24 hours by tail vein bleeding for urea nitrogen and TNF- $\alpha$ measurement. Animals were sacrificed at different time intervals, and the tissue was processed for histology, RNA isolation, and TNF- $\alpha$ measurement.

Blood urea nitrogen measurement. Blood urea nitrogen was measured using a commercially available kit (Sigma-Aldrich).

Ribonuclease protection assay. The expression of multiple genes was studied by multiprobe ribonuclease protection assay (RPA) using the Mck1b, Mck3b, and Mck5 DNA template sets according to the manufacturer's instructions (PharMingen, San Diego, California, USA).
Yeast tRNA was included in each experiment as a negative control. Protected fragments were resolved in a 6\% polyacrylamide-urea gel. The dried gel was exposed to $\mathrm{x}$-ray film, and the resulting bands were quantitated by laser densitometry.

Quantitation of $m R N A$ by real-time RT-PCR. Real-time RT-PCR was performed in an Applied Biosystems Inc. 7700 Sequence Detection System (Foster City, California, USA). Five micrograms total RNA was reverse transcribed in a reaction volume of $20 \mu \mathrm{l}$ using Superscript II reverse transcriptase and random primers. The product was diluted to a volume of $500 \mu \mathrm{l}$ and either $2-\mu \mathrm{l}$ (actin) or 10- $\mu \mathrm{l}$ (all others) aliquots were used as templates for amplification using the SYBR Green PCR amplification reagent (Applied Biosystems) and gene-specific primers. The primer sets used were: mouse IL-1 $\alpha$ (forward: CTCTAGAGCACCATGCTACAGAC; reverse: TGGAATCCAGGGGAAACACTG), IL-1 $\beta$ (forward: CTCCATGAGCTTTGTACAAGG; reverse: TGCTGATGTACCAGTTGGGG), IL-18 (forward: ACTGTACAACCGCAGTAATACGG; reverse: AGTGAACATTACAGATTTATCCC), and ICAM-1 (forward: AGATCACATTCACGGTGCTG; reverse: CTTCAGAGGCAGGAAACAGG). The amount of DNA was normalized to the $\beta$-actin signal amplified in a separate reaction (forward primer: CATGGATGACGATATCGCT; reverse: CATGAGGTAGTCTGTCAGGT).

TNF- $\alpha$ quantitation by ELISA. The levels of TNF- $\alpha$ in tissue, urine, and serum were quantitated using an ELISA assay (Quantikine Mouse TNF- $\alpha$ kit; R\&D Systems Inc., Minneapolis, Minnesota, USA). For measurement of kidney TNF- $\alpha$, kidney tissue was homogenized in PBS containing $0.05 \%$ Tween-20. Aliquots containing $300 \mu \mathrm{g}$ of total protein were used for the TNF- $\alpha$ assay.

Histology and immunohistochemistry. Kidney tissue was fixed in buffered formalin for 12 hours and then embedded in paraffin wax. Five-micrometer sections were stained with PAS or naphthol AS-D chloroacetate esterase (kit no. 91A; Sigma-Aldrich). The esterase stain identifies infiltrating neutrophils and monocytes. Thirty $\times 40$ fields of esterase-stained sections were examined for quantitation of leukocytes. Tubular injury was assessed in periodic acid-Schiff-stained (PAS-stained) sections using a semiquantitative scale $(11,19,20)$ in which the percentage of cortical tubules showing epithelial necrosis was assigned a score: $0=$ normal; $1=\langle 10 \% ; 2=10-25 \% ; 3=26-75 \% ; 4=>75 \%$. The individual scoring the slides was blinded to the treatment and strain of the animal.

Statistical methods. All assays were performed in duplicate. The data are reported as mean \pm SEM. Statistical significance was assessed by unpaired, two-tailed Student $t$ tests for single comparisons or ANOVA for multiple comparisons.

\section{Results}

Cytokine expression in cisplatin nephrotoxicity. Kidneys were harvested $6,24,48$, and 72 hours after injection of cisplatin. Cytokine gene expression was determined either 


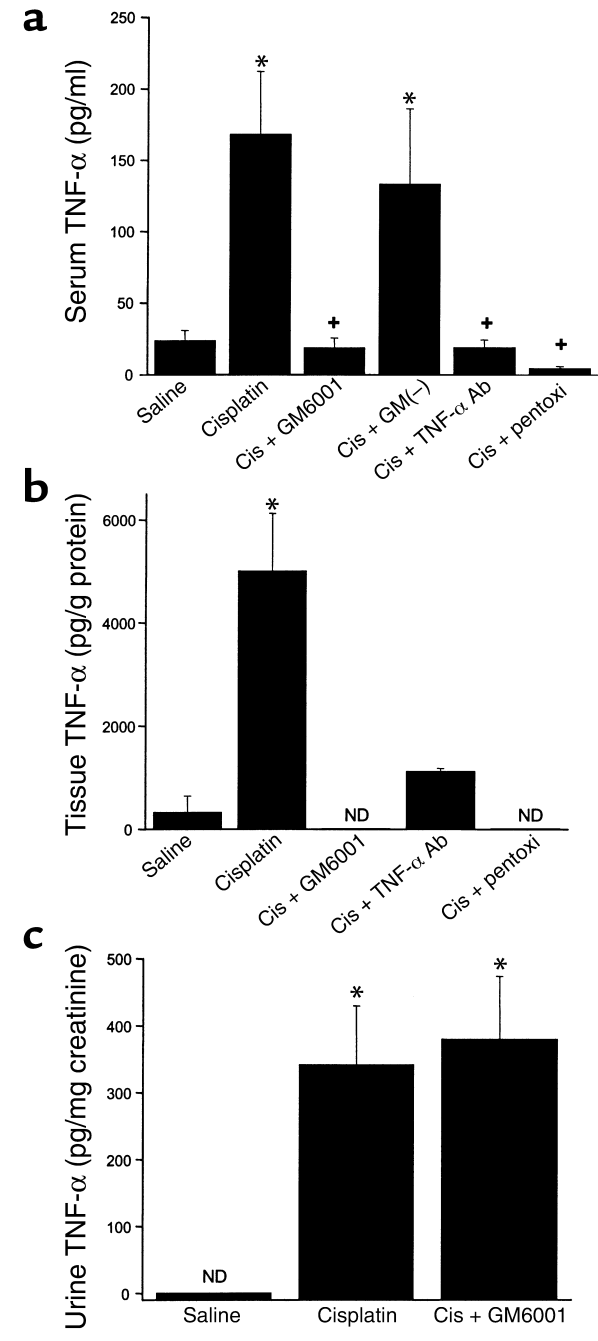

Figure 2

Levels of TNF- $\alpha$ in serum (a), kidney (b), and urine (c). GM(-) is a structural analogue of GM6001 that does not inhibit TACE. All levels were measured 72 hours after injection. ND, not detectable. ${ }^{*} P<0.01$ vs. saline, ${ }^{+} P<0.01$ vs. cisplatin. (a) $n=4-15$; (b) $n=2-9$; (c) $n=7-15$. GM6001(-), GM(-); cis, cisplatin; pentoxi, pentoxifylline.

by RPA or by real-time RT-PCR. Figure 1 shows a series of RPA assays using templates for the detection of cytokine genes. A number of cytokine transcripts, e.g., TNF- $\alpha$, RANTES, MCP-1, IP-10, TCA3, and MIP-2, were upregulated. In most cases, the upregulation was evident 24-48 hours after injection. Upregulation was often sustained to 72 hours, though in some cases, e.g., MCP-1 and IP-10, the peak of expression occurred by $24-48$ hours and was decreasing by 72 hours. RT-PCR indicated that IL- $1 \beta$ and ICAM- 1 were upregulated 27 -fold and 7.6-fold, respectively, at 72 hours (see Figure 4). In contrast, IL-1 $\alpha$ and IL-18 showed no consistent change in expression.

TNF- $\alpha$ in serum, urine, and kidney tissue. The role of TNF- $\alpha$ in toxic nephropathy is unknown. As noted above, we found TNF- $\alpha$ mRNA was increased in cisplatin nephrotoxicity, consistent with a recent report by Deng et al. (12). We also measured TNF- $\alpha$ protein levels in serum, kidney, and urine. As shown in Figure $2 \mathrm{a}$, serum levels of TNF- $\alpha$ were increased approximately eightfold in cisplatin-treated animals. Levels of TNF- $\alpha$ within the kidney (Figure $2 b$ ) were increased to an even greater extent. Figure 2 also shows the effects of GM6001, pentoxifylline, and neutralizing TNF- $\alpha$ $A b$ 's on the levels of TNF- $\alpha$. GM6001 is an inhibitor of TACE, or ADAM-17, the enzyme responsible for cleavage and release of membrane-anchored TNF- $\alpha$ into the circulation (21). GM6001 almost completely prevented the increase in both serum and kidney TNF- $\alpha$ content after cisplatin injection. An inactive structural analogue of GM6001 had no effect on serum TNF- $\alpha$ levels. Pentoxifylline and the TNF- $\alpha$ Ab also inhibited the rise in serum and tissue TNF- $\alpha$ levels. Urine TNF- $\alpha$ (Figure 2c) was undetectable in saline-treated mice and was markedly increased in mice injected with cisplatin. In contrast to its effects on serum and kidney TNF- $\alpha$, GM6001 did not reduce urine TNF- $\alpha$.

Role of TNF- $\alpha$ in cisplatin-induced gene expression. The results above indicate that several cytokines, including TNF- $\alpha$, are upregulated in cisplatin-induced renal injury. Many of the upregulated genes are known to be controlled by TNF- $\alpha$ (22). To determine if cytokine gene expression in cisplatin renal injury is driven by TNF- $\alpha$, we determined the effects of GM6001 and pentoxifylline on cisplatin-induced cytokine expression. Cytokine expression was determined by either RPA (Figure 3) or quantitative RT-PCR as above. The results are summarized in Figure 4 and indicate that

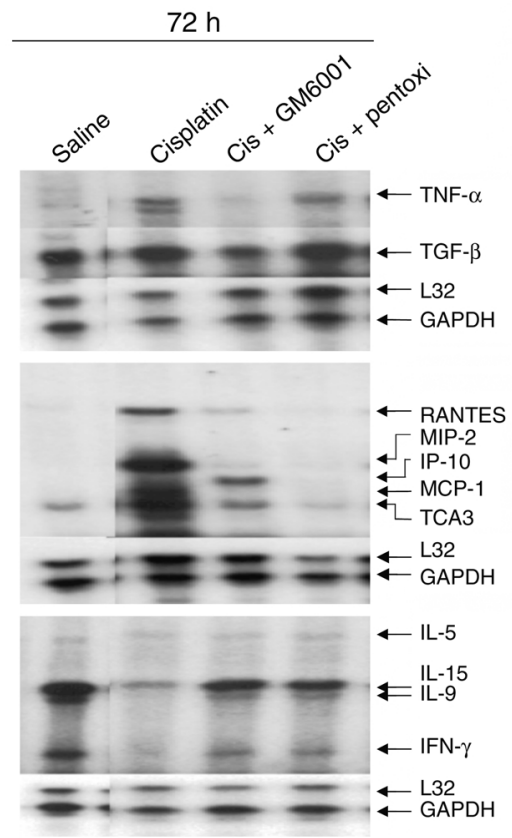

Figure 3

Effect of TNF- $\alpha$ inhibitors on renal cytokine expression. Mice were injected with either saline, cisplatin, or cisplatin with GM6001, or pentoxifylline and sacrificed at 72 hours. Cytokine transcripts were measured by RPA as in Figure 1. All lanes are from the same gel. Lanes 1 and 2 are shown in Figure 1 and are included here to facilitate comparison with the TNF- $\alpha$ inhibitor samples. 


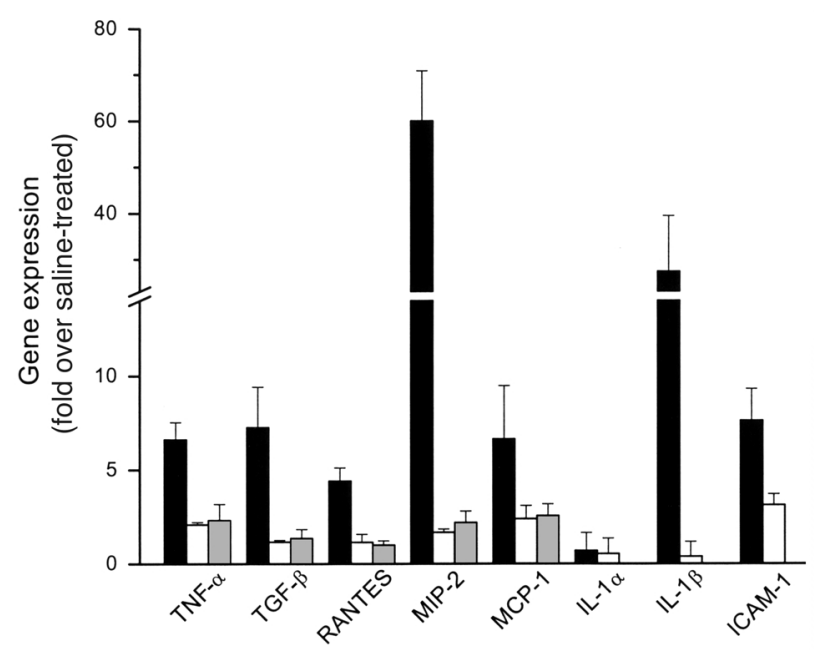

Figure 4

Effects of TNF- $\alpha$ inhibitors on cytokine gene expression. Cytokine gene expression was measured 72 hours after injection of cisplatin (black bars) or cisplatin and either GM6001 (white bars) or pentoxifylline (gray bars) by either RPA or real-time RT-PCR. In each experiment, the expression levels were normalized to the expression of either GAPDH or actin and are expressed relative to saline-treated control mice. $n=3-5$ for each condition.

the cisplatin-induced increases in TNF- $\alpha$, TGF- $\beta$, RANTES, MIP-2, MCP-1, and IL-1 $\beta$ were blunted by the TNF- $\alpha$ inhibitors. In contrast, the TNF- $\alpha$ inhibitors did not reduce significantly ICAM-1 mRNA. Effect of TNF- $\alpha$ antagonists on cisplatin-induced renal dysfunction. To address the role of TNF- $\alpha$ in the pathogenesis of cisplatin-induced acute renal failure, renal function was measured in animals treated with cisplatin in the presence or absence of GM6001 or a neutralizing TNF- $\alpha$ Ab. As shown in Figure 5, the TNF- $\alpha$ inhibitors reduced the blood urea concentrations in mice treated with cisplatin. The more effective of these agents, GM6001, reduced the urea concentration by over $50 \%$. The improvement in renal function was also reflected in less severe histologic damage (Figure 6). Cisplatin treatment resulted in severe tubular injury reflected by cast formation, loss of brush border membranes, sloughing of tubular epithelial cells, and dilation of tubules. These changes were absent in kidneys from animals injected with cisplatin and GM6001. Semiquantitative assessment of histologic injury yielded tubular necrosis scores of $0.05 \pm 0.05$ in saline-treated mice, $3.2 \pm 0.3$ in cisplatin-treated mice, and $0.6 \pm 0.1$ in mice treated with cisplatin and GM6001. The differences between the cisplatin-treated mice and either the saline or cisplatin plus GM6001-treated mice were significant $(P<0.004, n=2-8)$.

Cisplatin nephrotoxicity in TNF- $\alpha$ knockout mice. The previous experiments used pharmacologic and immunologic means of inhibiting TNF- $\alpha$ secretion and/or action. The pharmacologic agents we employed are not specific for TNF- $\alpha$. Pentoxifylline, for example, can affect blood flow (23) and the secretion of IL-1, IL-6, IL-8, and IL-10 (24). GM6001 may inhibit metalloproteinases other than TACE. In addition, TACE has a number of substrates other than membrane-bound TNF- $\alpha(25,26)$. To confirm that the effects of these agents on cisplatin nephrotoxicity were mediated through TNF- $\alpha$, we used mice in which the TNF- $\alpha$ gene had been genetically inactivated (17). In the wild-type strain, cisplatin produced severe renal failure (Figure 7) and marked histologic evidence of renal tubular necrosis (Figure 8). In comparison, the TNF- $\alpha$ knockout mice demonstrated significantly less renal functional impairment (Figure 7) and developed much less pronounced histologic damage (Figure 8) after injection with cisplatin. The tubular necrosis scores for the cisplatin-treated TNF- $\alpha$ knockout mice $(0.9 \pm 0.6)$ were significantly less than for the cisplatin-treated wild-type mice $(3.4 \pm 0.3, P=0.014$, $n=3$ for each group).

Lenkocyte infiltration in cisplatin nephrotoxicity. Leukocyte infiltration was measured using the napthol AS-D chloroacetate esterase stain. As shown in Figure 9, in either Swiss-Webster or in TNF- $\alpha$ wild-type mice, cisplatin injection produced a large increase in leukocytes within the kidney cortex. In contrast, TNF- $\alpha$ knockout mice, or mice treated with GM6001, had little or no increase in leukocytes.

\section{Discussion}

Cytokines and chemokines form complex regulatory networks characterized by both positive- and negative-feedback relations between the various elements of the network. The elements of a renal cytokine network that may be active in cisplatin nephrotoxicity have not been defined. In addition, the role of cytokines in the pathogenesis of cisplatin nephrotoxicity has not been established. Accordingly, the present studies had two major goals. First, we determined the effect of cisplatin administration on the expression of a broad array of cytokines and chemokines within the kidney. Second, having noted

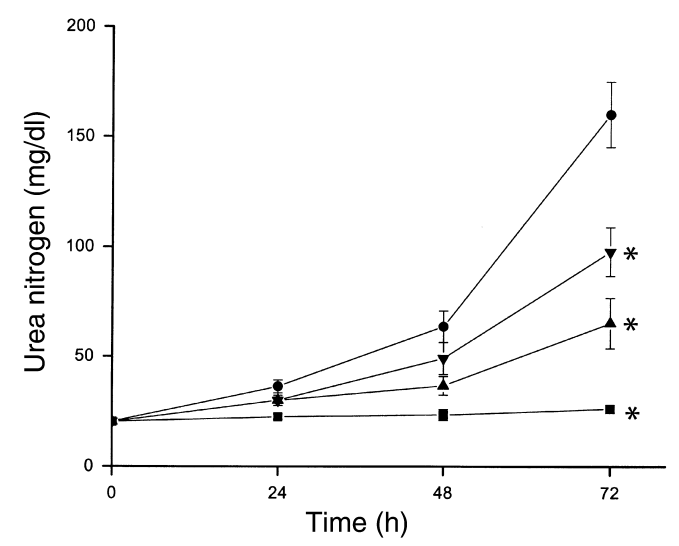

Figure 5

Effect of TNF- $\alpha$ inhibitors on cisplatin nephrotoxicity. Mice were injected with saline (squares), $20 \mathrm{mg} / \mathrm{kg}$ cisplatin (circles), cisplatin and GM6001 (triangles), or neutralizing TNF- $\alpha$ Ab (inverted triangles), as described in Methods. Blood urea nitrogen was measured at the indicated times. ${ }^{*} P<0.01$ vs. cisplatin, $n=4-7$. 

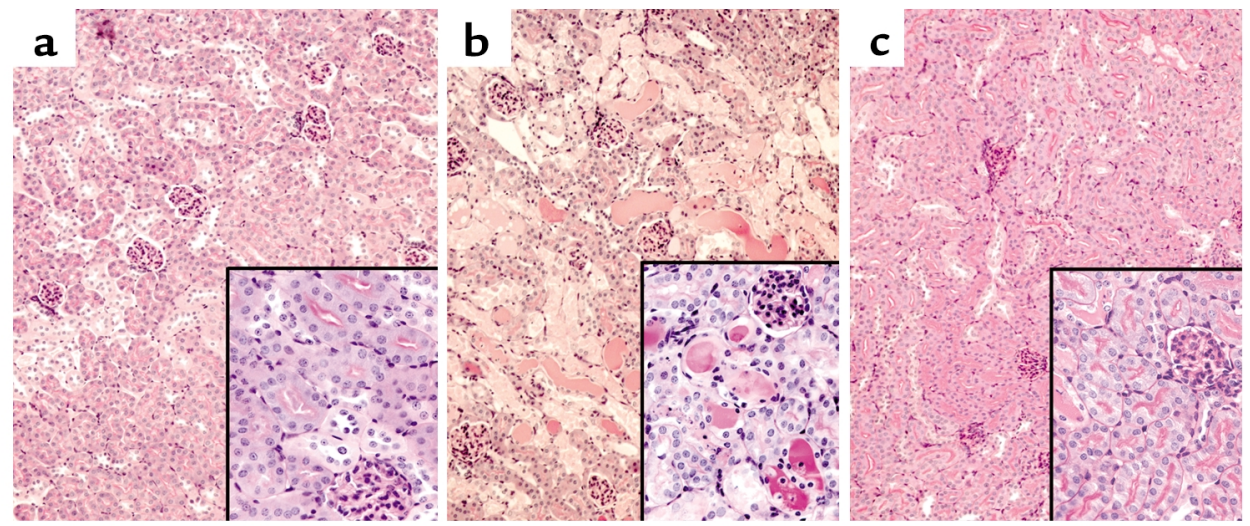

\section{Figure 6}

Effects of cisplatin and TNF- $\alpha$ inhibitors on kidney morphology. Kidneys were removed 72 hours after injection with saline (a), cisplatin (b), or cisplatin and GM6001 (c). (a) Saline-treated kidneys show normal morphology with well-preserved brush border membranes and no loss of tubular epithelial cells. (b) Cisplatin-treated kidneys show extensive loss of tubular epithelial cells, tubular dilation, intratubular debris, and cast formation. (c) Kidneys from cisplatin plus GM6001 mice show relatively normal morphology. Sections were stained with PAS and photographed at $\times 100$ magnification (inset, $\times 400$ ).

that TNF- $\alpha$ was increased at the RNA and protein level following cisplatin administration, we examined the possible role of TNF- $\alpha$ in cisplatin nephrotoxicity. Several results are noteworthy.

First, several cytokines and chemokines were upregulated in the kidney in association with cisplatininduced acute renal failure. As reported by Deng et al. (12), we found that mRNA levels for TNF- $\alpha$ were increased by cisplatin. In addition, levels of IL- $1 \beta$, RANTES, MIP-2, MCP- 1 , TCA3, TGF- $\beta 1$, and IP- 10 mRNA were increased. Of these, only an increase in IP-10 had been noted previously in cisplatin nephrotoxicity (27). Lemay et al. (28) and Takada et al. (29) have examined cytokine expression in renal ischemiareperfusion injury. As in cisplatin toxicity, increases in TNF- $\alpha$, IL- $1 \beta$, MCP-1, and MIP- 2 occurred, albeit with different kinetics. Only small increases in either RANTES or IL- $1 \alpha$ expression were seen in ischemiareperfusion $(28,29)$, while IL- 6 and IL-11 were upregulated in ischemia-reperfusion but not in cisplatin nephrotoxicity. The reasons for the differences in cytokine expression and the pathophysiologic significance of these differences remains to be determined. It is possible that the different patterns of expression reflect differences in the cellular sources of cytokine production, e.g., infiltrating leukocytes versus renal parenchymal cells, in the two models. In this regard, the sites of expression of the various cytokines in either ischemia-reperfusion injury or cisplatin toxicity are unknown. TNF- $\alpha$ and IL- $1 \beta$ are proinflammatory cytokines and are often elevated in parallel. Indeed, TNF- $\alpha$ and IL- $1 \beta$ stimulate the production of one another (22) and act synergistically to stimulate the production of other cytokines and chemokines (30). RANTES, MCP-1, and MIP-2 are chemotactic for a variety of leukocytes, including neutrophils, monocytes, natural killer cells, and T lymphocytes (31). Which of these leukocyte populations may participate in cisplatin nephrotoxicity is unknown. In the case of ischemia-reperfusion injury, evidence exists implicating both neutrophils and lymphocytes $(10,19,20,32)$.

Second, levels of TNF- $\alpha$ in the serum, kidney tissue, and urine were increased after cisplatin injection. Increases in serum TNF- $\alpha$ were reported by Kelly et al. (19) in a model of ischemia-reperfusion injury. However, elevations in serum and urine TNF- $\alpha$ concentrations have not been reported in toxic nephropathy. As will be discussed, elevated renal expression of TNF- $\alpha$ appears to play a pathogenic role in cisplatin nephrotoxicity. Further studies will be required to determine if measurement of serum or urine TNF- $\alpha$ levels may have value in identifying individuals with early cisplatin nephrotoxicity.

Third, inhibition of TNF- $\alpha$ release or TNF- $\alpha$ activity afforded protection from cisplatin nephrotoxicity.

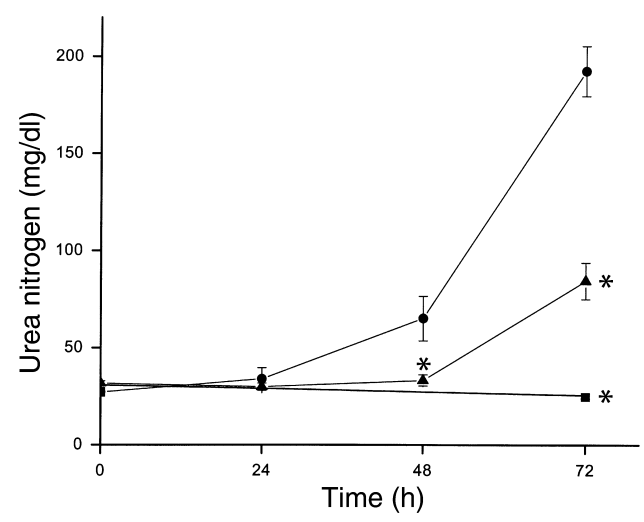

\section{Figure 7}

Cisplatin nephrotoxicity in wild-type (circles) or TNF- $\alpha$ knockout (triangles, squares) mice. Mice were injected with saline (squares) or 20 $\mathrm{mg} / \mathrm{kg}$ cisplatin (circles, triangles). Blood urea nitrogen was measured at the indicated times. ${ }^{*} P<0.01$ vs. wild-type cisplatin-injected mice, $n=4-7$. 


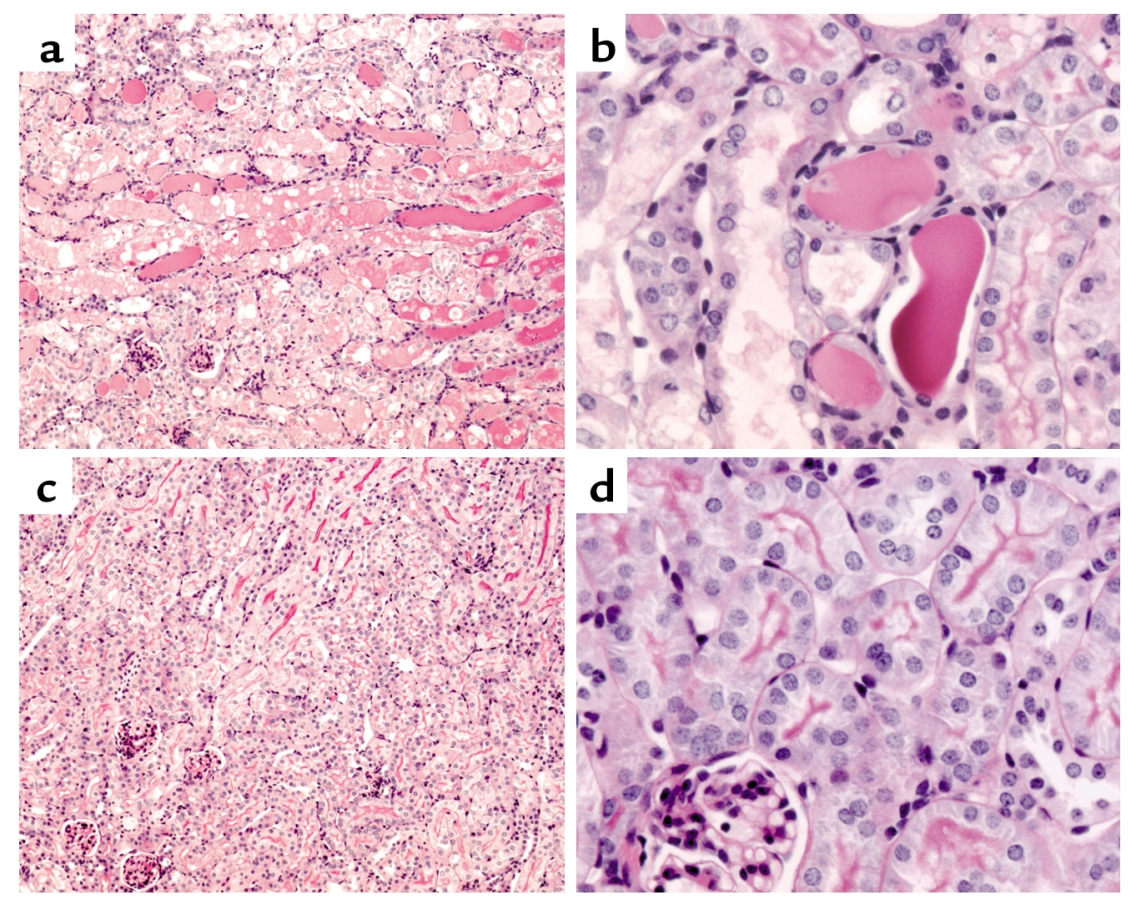

Figure 8

Effect of cisplatin on kidney morphology in wild-type and TNF- $\alpha$ knockout mice. ( $\mathbf{a}$ and $\mathbf{b}$ ) Wild-type mice exhibit severe tubular necrosis, tubular dilation, and cast formation throughout the cortex. ( $c$ and $\mathbf{d}$ ) TNF- $\alpha$ knockout mice have well-preserved renal morphology. Kidneys were removed 72 hours after injection with cisplatin. Sections were stained with PAS and photographed at $\times 100$ magnification ( $\mathbf{a}$ and $\mathbf{c}$ ) or $\times 400$ magnification (b and d).
These results were confirmed in mice lacking a functional TNF- $\alpha$ gene. Taken together, these results provide strong support for the view that TNF- $\alpha$ is an important component in the mechanism of cisplatin nephrotoxicity. These results are consistent with the observations that $\alpha \mathrm{MSH}$ and IL-10, which suppress the formation of proinflammatory cytokines (33), including TNF- $\alpha$, ameliorate cisplatin toxicity (12). Recent reports suggest that TNF- $\alpha$ may play a role in acute renal ischemic $(34,35)$ and endotoxemic (36) injury, as well. Inhibition of TNF- $\alpha$ action, either with a TNF-binding protein (34) or neutralizing Ab's (35), reduced ischemic injury in rats. In contrast, neutralization of IL-10, which suppresses TNF- $\alpha$ production, exacerbated ischemic injury (35). We note that the TNF- $\alpha$ inhibitors reduced but did not completely prevent cisplatin nephrotoxicity. The failure of anti-TNF- $\alpha$ treatments to provide complete protection against cisplatin-induced injury likely reflects the presence of TNF- $\alpha$-independent pathways of cisplatin injury.

Comparisons of the effects of TNF- $\alpha$ inhibition with other maneuvers reported to ameliorate cisplatin renal injury are difficult due to methodologic differences that include the cisplatin dose, administration schedule, and species or strain of animal. The protection noted in the present study was similar to that observed using anti-ICAM-1 Ab's (11), iron chelators (13), or heme oxygenase induction (37), but somewhat less than that from IL-10 (12). Of interest, TNF- $\alpha$ inhibition was more effective in reducing cisplatin injury (this study) than ischemic renal injury $(34,35)$. It may not be possible to generalize the results of this study to other forms of toxic acute renal failure. For example, in mercuric chloride-induced renal injury, ICAM-1 Ab's (38), $\alpha \mathrm{MSH}$ and IL-10 (39), had no protective effect and anti-TNF- $\alpha$ Ab's had only a modest protective effect (40).

The mechanism whereby TNF- $\alpha$ contributes to cisplatin renal injury is not clear. TNF- $\alpha$ could itself cause injury to renal epithelial cells. TNF- $\alpha$ is capable of inducing apoptosis in a renal epithelial cells $(41,42)$. At low concentrations, cisplatin induces apoptosis in cultured renal epithelial cells $(6,7,43)$. Moreover, cisplatin

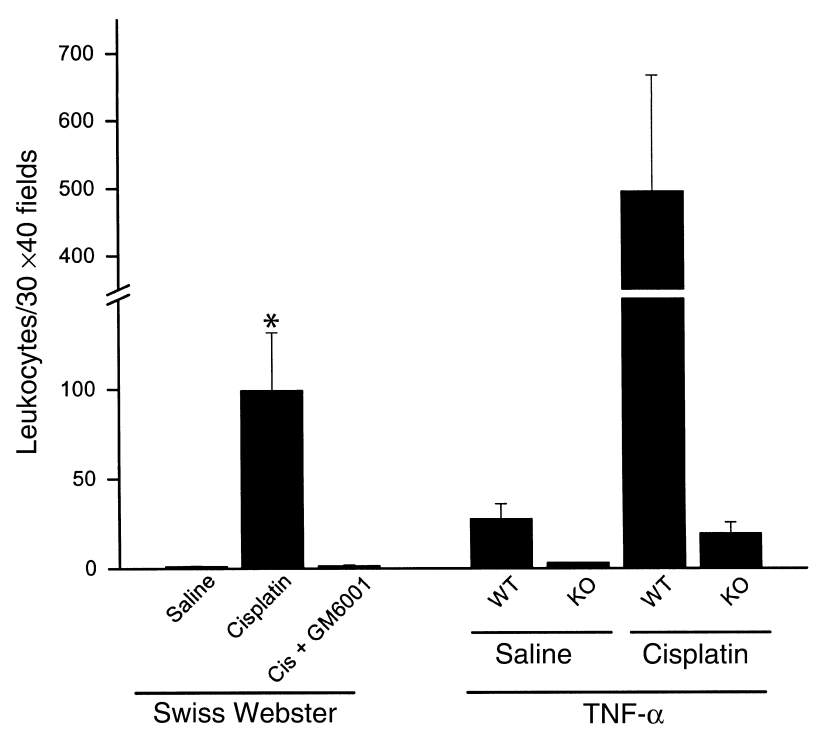

Figure 9

TNF- $\alpha$ dependence of leukocyte infiltration in cisplatin nephrotoxicity. Sections of kidney harvested 72 hours after injection were stained for leukocytes as described in Methods. Thirty $\times 40$ fields of kidney cortex were examined from each animal. The total number of leukocytes in those 30 fields is presented in the figure. ${ }^{*} P<0.02$ vs. saline or cisplatin plus GM6001. $n=2-7$. WT, wild type; KO, knockout. 
activates caspase 8 , typically associated with activation of TNF- $\alpha$ or Fas receptors (6). In preliminary studies (not shown) we have shown that cisplatin can induce the production and release of TNF- $\alpha$ by renal epithelial cells in vitro. Thus, it is possible that autocrine production of TNF- $\alpha$ may mediate a portion of cisplatininduced apoptosis in renal epithelial cells.

Strong evidence supports a role for reactive oxygen species in the pathogenesis of cisplatin nephrotoxicity (13-15). TNF- $\alpha$ stimulates the production of reactive oxygen species (44). However, the role of reactive oxygen species in TNF- $\alpha$ toxicity is unclear because free radical scavengers can either decrease (44) or increase (45) TNF- $\alpha$ cytotoxicity. TNF- $\alpha$ could also produce oxidant stress by sensitizing infiltrating leukocytes so they respond with increased oxidant formation (46). Moreover, oxidant stress may increase the production of TNF- $\alpha$ and other cytokines by activation of NFKB (47). For example, iron chelators, shown to reduce cisplatin injury (13), also reduce LPS-stimulated TNF- $\alpha$ release from mesangial cells (48). Thus, TNF- $\alpha$ could either result from or cause oxidant injury in cisplatin nephrotoxicity.

Finally, TNF- $\alpha$ may contribute to cisplatin nephrotoxicity by inciting an inflammatory response within the kidney. The upregulation of IL-1 $\beta$, RANTES, MCP-1, and MIP- 2 by TNF- $\alpha$ may promote the migration of inflammatory cells into the renal parenchyma. The absence of upregulation of these molecules in mice treated with TNF- $\alpha$ antagonists and the decrease in leukocyte infiltration in TNF- $\alpha$-deficient mice supports this possibility. Confirming earlier reports $(11,12)$, we also found an increase in ICAM-1 expression in cisplatintreated kidneys. However, ICAM-1 expression was not appreciably diminished by TNF- $\alpha$ antagonists (Figure 4) or in the TNF- $\alpha$ knockout mice (not shown), indicating that ICAM-1 expression is not TNF- $\alpha$ dependent in this model. This result is similar to that found by Burne et al. (49) in a murine model of ischemia-reperfusion injury. In that study, mice lacking both the TNF-R1 and IL-1R1 had lower neutrophil infiltration at 24 hours after reperfusion compared with wild-type mice, but ICAM-1 expression was increased to a similar extent in both sets of mice. Thus, ICAM- 1 expression in the kidney appears to be TNF- $\alpha$ independent and may be necessary $(11,19)$, but not sufficient (49), for leukocyte-mediated injury in acute renal failure.

In summary, we have shown that cisplatin induces the expression of a variety of inflammatory chemokines and cytokines, including TNF- $\alpha$, within the kidney. Blockade of TNF- $\alpha$ action prevented the upregulation of these other cytokines and also ameliorated cisplatin nephrotoxicity. These results demonstrate an important role for TNF- $\alpha$ in cisplatin nephrotoxicity. These findings are of particular interest given the availability of anti-TNF- $\alpha$ therapies for use in humans. Additional studies to examine the role of TNF- $\alpha$ in human cisplatin nephrotoxicity are warranted.

\section{Acknowledgments}

This work was supported by the Veterans Affairs Medical Research Service and grants from the American Heart Association and the Four Diamonds Fund. We thank Sudhir V. Shah for his comments and suggestions during the preparation of this manuscript.

1. Lebwohl, D., and Canetta, R. 1998. Clinical development of platinum complexes in cancer therapy: an historical perspective and an update. Eur. J. Cancer. 34:1522-1534.

2. Ries, F., and Klastersky, J. 1986. Nephrotoxicity induced by cancer chemotherapy with special emphasis on cisplatin toxicity. Am.J. Kidney Dis. 8:368-379.

3. Leibbrandt, M.E., Wolfgang, G.H., Metz, A.L., Ozobia, A.A., and Haskins, J.R. 1995. Critical subcellular targets of cisplatin and related platinum analogs in rat renal proximal tubule cells. Kidney Int. 48:761-770.

4. Sugiyama, S., et al. 1989. Adverse effects of anti-tumor drug, cisplatin, on rat kidney mitochrondria: disturbances in glutathione peroxidase activity. Biochem. Biophys. Res. Commun. 159:1121-1127.

5. Matsushima, H., Yonemura, K., Ohishi, K., and Hishida, A. 1998. The role of oxygen free radicals in cisplatin-induced acute renal failure in rats. J. Lab. Clin. Med. 131:518-526.

6. Kaushal, G., Kaushal, V., Hong, X., and Shah, S. 2001. Role and regulation of activation of caspases in cisplatin-induced injury to renal tubular epithelial cells. Kidney Int. 60:1726-1736.

7. Lieberthal, W., Triaca, V., and Levine, J. 1996. Mechanisms of death induced by cisplatin in proximal tubular eipthelial cells: apoptosis vs. necrosis. Am. J. Physiol. Renal Physiol. 270:F700-F708.

8. Okuda, M., Masaki, K., Fukatsu, S., Hashimoto, Y., and Inui, K. 2000. Role of apoptosis in cisplatin-induced toxicity in the renal epithelial cell line LLC-PK 1 . Biochem. Pharmacol. 59:195-201.

9. Sheridan, A., and Bonventre, J. 2000. Cell biology and molecular mechanisms of injury in ischemic acute renal failure. Curr. Opin. Nephrol. Hyperten. 9:427-434.

10. Burne, M.J., et al. 2001. Identification of the $\mathrm{CD} 4^{+} \mathrm{T}$ cell as a major pathogenic factor in ischemic acute renal failure. J. Clin. Invest. 108:1283-1290. doi:10.1172/JCI200112080.

11. Kelly, K.J., Meehan, S.M., Colvin, R.B., Williams, W.W., and Bonventre, J.V. 1999. Protection from toxicant-mediated renal injury in the rat with anti-CD54 antibody. Kidney Int. 56:922-931.

12. Deng, J., et al. 2001. Interleukin-10 inhibits ischemic and cisplatininduced acute renal injury. Kidney Int. 60:2118-2128.

13. Baliga, R., Zhang, Z., Baliga, M., Ueda, N., and Shah, S.V. 1998. In vitro and in vivo evidence suggesting a role for iron in cisplatin-induced nephrotoxicity. Kidney Int. 53:394-401.

14. Shiraishi, F., et al. 2000. Heme oxygenase-1 gene ablation or expression modulates cisplatin-induced renal tubular apoptosis. Am. J. Physiol. Renal Physiol. 278:F726-F736.

15. Davis, C., Nick, H., and Agarwal, A. 2001. Manganese superoxide dismutase attenuates cisplatin-induced renal injury: importance of superoxide. J. Am. Soc. Nephrol. 12:2683-2690.

16. Barnes, P., and Karin, M. 1997. Nuclear factor- $k$ B: a pivotal transcription factor in chronic inflammatory diseases. New Engl. J. Med. 336:1066-1071.

17. Pasparakis, M., Alexopoulou, L., Episkopou, V., and Kollias, G. 1996. Immune and inflammatory responses in TNF $\alpha$-deficient mice: a critical requirement for TNF $\alpha$ in the formation of primary B cell follicles, follicular dendritic cell networks and germinal centers, and in the maturation of the humoral immune response. J. Exp. Med. 184:1397-1411.

18. Megyesi, J., Safirstein, R.L., and Price, P.M. 1998. Induction of p21WAF1/CIP1/SDI in kidney tubule cells affects the course of cisplatin-induced acute renal failure. J. Clin. Invest. 101:777-782.

19. Kelly, K.J., Williams, W.W., Colvin, R.B., and Bonventre, J.V. 1994. Antibody to intercellular adhesion molecule- 1 protects the kidney against ischemic injury. Proc. Natl. Acad. Sci. USA. 91:812-816.

20. Rabb, H., et al. 2000. Pathophysiological role of T lymphocytes in renal ischemia-reperfusion injury in mice. Am. J. Physiol. Renal Physiol. 279:F525-F531.

21. Reddy, P., et al. 2000. Functional analysis of the domain structure of tumor necrosis factor- $\alpha$ converting enzyme. J. Biol. Chem. 275:14608-14614.

22. Aggarwal, B.B., Samanta, A., and Feldmann, M. 2001. TNF $\alpha$. In Cytokine reference. Volume 1. J.J. Oppenheim and M. Feldmann, editors. Academic Press. San Diego, California, USA. 413-434.

23. Porter, J.M., et al. 1982. Pentoxyfylline efficacy in the treatment of intermittent claudication. Am. Heart J. 104:66-72.

24. Lefebvre D'Hellencourt, C., Diaw, L., Cornillet, P., and Guenounou, M. 1996. Differential regulation of TNF $\alpha$, IL-1 $\beta$, IL-6, IL-8, TNF $\beta$, and IL10 by pentoxifylline. Int. J. Immunopharmacol. 18:739-748. 
25. Black, R.A. 2002. Tumor necrosis factor-alpha converting enzyme. Int.J. Biochem. Cell Biol. 34:1-5.

26. Brou, C., et al. 2000. A novel proteolytic cleavage involved in Notch signaling: the role of the disintegrin-metalloprotease TACE. Mol. Cell. 5:207-216.

27. Huang, Q., et al. 2001. Assessment of cisplatin-induced nephrotoxicity by microarray technology. Toxicol. Sci. 63:196-207.

28. Lemay, S., Rabb, H., Postler, G., and Singh, A. 2000. Prominent and sustained up-regulation of ${ }_{\mathrm{GP}} 130$-signaling cytokines and of the chemokine MIP-2 in murine renal inschemia-reperfusion injury. Transplantation. 69:959-963.

29. Takada, M., Nadeau, K., Shaw, G., Marquette, K., and Tilney, N. 1997. The cytokine-adhension molecule cascade in ischemia/reperfusion injury of the rat kidney. J. Clin. Invest. 99:2682-2690.

30. Banas, B., et al. 1999. Chemokine and chemokine receptor expression in a novel human mesangial cell line. J. Am. Soc. Nephrol. 10:2314-2322.

31. Rovin, B., and Phan, L. 1998. Chemotactic factors and renal inflammation. Am. J. Kidney Dis. 31:1065-1084.

32. Paller, M.S. 1989. Effect of neutrophil depletion on ischemic renal injury in the rat. J. Lab. Clin. Med. 113:379-386.

33. de Waal Malefyt, R. 2001. IL-10. In Cytokine reference. Volume 1. J.J. Oppenheim and M. Feldmann, editors. Academic Press. San Diego, California, USA. 165-185.

34. Donnahoo, K., et al. 1999. Early kidney TNF- $\alpha$ expression mediates neutrophil infiltration and injury after renal ischemia-reperfusion. Am.J. Physiol. 277:R922-R929.

35. Daemen, M., Ven, M., Heineman, E., and Buurman, W. 1999. Involvement of endogenous interleukin-10 and tumor necrosis factor- $\alpha$ in renal ischemia-reperfusion injury. Transplantation. 67:792-799.

36. Knotek, M., et al. 2001. Endotoxemic renal failure in mice: role of tumor necrosis factor independent of inducible nitric oxide synthase. Kidney Int. 59:2243-2249.

37. Agarwal, A., Balla, J., Alam, J., Croatt, A.J., and Nath, K.A. 1995. Induction of heme oxygenase in toxic renal injury: a protective role in cisplatin nephrotoxicity in the rat. Kidney Int. 48:1298-1307.

38. Ghielli, M., et al. 1999. Antibodies to both ICAM-1 and LFA-1 do not protect the kidney against toxic $\left(\mathrm{HgCl}_{2}\right)$ injury. Kidney Int. 58:1121-1134.
39. Miyaji, T., Hu, X., and Star, R. 2002. $\alpha$-Melanocyte-simulating hormone and interleukin-10 do not protect the kidney against mercuric chlorideinduced injury. Am J. Physiol. Renal Physiol. 282:F795-F801.

40. Yanagisawa, H., Nodera, M., Umemori, Y., Shimoguchi, Y., and Wada, O. 1998. Role of angiotensin II, endothelin-1, and nitric oxide in $\mathrm{HgCl}_{2-}$ induced acute renal failure. Toxicol. Appl. Pharmacol. 152:315-326.

41. Ortiz, A., et al. 2000. Expression of apoptosis regulatory proteins in tubular epithelium stressed in culture or following acute renal failure. Kidney Int. 57:969-981.

42. Soler, A.P., Mullin, J.M., Knudsen, K.A., and Marano, C.W. 1996. Tissue remodeling during tumor necrosis factor-induced apoptosis in LLC-PK renal epithelial cells. Am. J. Physiol. Renal Physiol. 270:F869-F879.

43. Zhan, Y., Water, B., Wang, Y., and Stevens, J. 1999. The roles of caspase3 and bcl-2 in chemically-induced apoptosis but not necrosis of renal epithelial cells. Oncogene. 18:6505-6512.

44. Goossens, V., Grooten, J., Vos, K., and Fiers, W. 1995. Direct evidence for tumor necrosis factor-induced mitochondrial reactive oxygen intermediates and their involvement in cytotoxicity. Proc. Natl. Acad. Sci. USA. 92:8115-8119.

45. Bai, J., and Cederbaum, A.I. 2000. Overexpression of catalase in the mitochondrial or cytosolic compartment increases sensitivity of HepG2 cells to tumor necrosis factor-alpha-induced apoptosis. J. Biol. Chem. 275:19241-19249.

46. Halliwell, B., and Gutteridge, J.M.C. 1990. Role of free radicals and catalytic metal ions in human disease: an overview. In Methods in enzymology. Volume 186. L. Packer and A.N. Glazer, editors. Academic Press. San Diego, California, USA. 1-88.

47. Manna, S.K., Zhang, H.J., Yan, T., Oberley, L.W., and Aggarwal, B.B. 1998. Overexpression of manganese superoxide dismutase suppresses tumor necrosis factor-induced apoptosis and activation of nuclear transcription factor-kappaB and activated protein-1. J. Biol. Chem. 273:13245-13254.

48. Baud, L., Fouqueray, B., Phillipe, C., and Affres, H. 1992. Modulation of tumor necrosis factor by reactive oxygen metabolites. News Physiol. Sci. 7:34-37.

49. Burne, M., et al. 2001. IL-1 and TNF independent pathways mediate ICAM-1/VCAM-1 up-regulation in ischemia reperfusion injury. J. Lenkocyte Biol. 70:192-198. 